\title{
El relato acerca de lo femenino y lo masculino en el cine chileno (2000-2016)
}

\section{An account of the male and female factor in Chilean cinema (2000-2016)}

\author{
Hudson Frías, E., Mezzera Regules, J. y Moreno, A. ${ }^{1}$ \\ Recibido: 31-08-2018 - Aceptado: 25-01-2019 \\ DOI: https://doi.org/10.26441/RC18.1-2019-A5
}

RESUMEN: Esta investigación trata acerca de la construcción de lo femenino y lo masculino en el cine contemporáneo chileno (2000-2016). A través de un análisis de contenido mixto se codificaron características demográficas y sociales de todos los personajes que tuvieran al menos una línea de diálogo $(\mathrm{N}=684)$ en un corpus compuesto por las 33 películas que lograron más de 100.000 espectadores. Se analizó la incidencia de la variable sexo en la construcción del objetivo dramático de los hombres y las mujeres presentes en el relato de la ficción audiovisual chilena y se comprobó así que la mediación que ha ejercido el cine durante este tiempo recrea y mantiene los estereotipos de género que padece en la actualidad la sociedad chilena.

Palabras clave: género; cine chileno; análisis de contenido; esfera pública; mediación.

ABSTRACT: This research deals with the construction of the feminine and masculine in contemporary Chilean cinema (2000-2016). Through a mixed content analysis, demographic and social characteristics of all the characters that had at least one line of dialogue $(N=684)$ were codified in a corpus composed of the 33 films that achieved more than 100,000 spectators. The incidence of the sex variable was analyzed in the construction of the dramatic objective of the men and women present in the story of the Chilean audiovisual fiction and it was verified that the mediation that the cinema has exercised during this time recreates and maintains the stereotypes of gender that Chilean society currently suffers.

Keywords: gender; chilean cinema; content analysis; public sphere; mediation.

\section{Introducción}

La primera producción audiovisual realizada y exhibida en Chile no estuvo protagonizada por una mujer ni hubo paridad de género en el resto del elenco. El título de la obra tampoco llevó un

1 Eileen Hudson Frías es Doctora en Comunicación Pública por la Universidad de Navarra (España). Es Profesor Asociado de la Facultad de Comunicaciones de la Universidad del Desarrollo (Chile) donde imparte las asignaturas de Metodología de la Investigación y Seminario de Investigación. ehudson@udd.cl, https://orcid.org/00000002-0820-9082.

Josefina Mezzera Regules es Magister en Guion Audiovisual por la Universidad de Navarra y asistente en la Facultad de Comunicación de la Universidad del Desarrollo pinamezzera@gmail.com

Andrea Moreno es Licenciada en Comunicaciones por la Universidad del Desarrollo. andrmorenom@udd.cl 
nombre femenino. La película se llamó Manuel Rodríguez (1910) y la intérprete "Filomena Flores" fue la única fémina que participó en esa producción. Esta primera cinta marcó el inicio de una historia que, un siglo después, ha registrado pocos cambios para las mujeres.

Cuando el cine chileno era mudo se personificaba a las mujeres como pasivas e indefensas, incluso de ellas mismas. En su mayoría eran seducidas, corrían peligro o necesitaban ser protegidas por su compañero del sexo opuesto. Estas características fueron los cimientos de lo que más tarde se conocería como estereotipos femeninos en la ficción audiovisual.

Más de 100 años después, las historias de aquellos primeros largometrajes no presentan cambios significativos en este ámbito. Si bien la técnica y el desarrollo de conflictos evolucionaron, no ocurrió lo mismo con los papeles femeninos.

La excepción acaba de ocurrir y es Una mujer fantástica, dirigida por Sebastián Lelio y producida por los hermanos Larraín (2017). Ganó el Óscar a la mejor película extranjera en 2018 y se convirtió en un ícono de la lucha por el reconocimiento de las personas transgénero. También obtuvo premios en el Festival Internacional de Cine de Berlín, en Cabourg, San Sebastián, Goya y La Habana, entre otros. Sin embargo, en diciembre de 2017 la película había alcanzado 43.842 espectadores en Chile, según datos oficiales $^{2}$.

El siguiente estudio se construye, a partir de la necesidad de evaluar de forma empírica la presencia y representación de la mujer en películas chilenas. Para ello se analizaron las cintas que superaron las 100.000 entradas vendidas y que se exhibieron entre 2000 y 2016. En el nuevo milenio, la cantidad de películas que superó la asistencia estipulada fue de 33 filmes.

\section{Marco teórico}

La producción cinematográfica crea cultura y entretiene y genera aquello que se conoce como disfrute mediático, que es un concepto que abarca las experiencias emocionales positivas que, según Cohen (2001), suceden a partir de instancias varias que tienen lugar durante los procesos de recepción. Entre ellas se incluye la posibilidad de involucrarse afectivamente con un personaje, identificarse con determinado aspecto de la historia o experimentar cercanía cultural con la trama que desarrolla el guion.

Esa es una de las características que explica la mediación que ejerce el cine, la que se origina en las razones que mueven a los realizadores a la hora de darle vida a un guion, elegir una escenografía o priorizar un aspecto $u$ otro de un personaje. A su vez, esa mediación tiene como destinatarias a las estructuras sociales que les son contemporáneas y con 2 Ref. Informe diciembre de 2017 de Chile Audiovisual. Disponible en https://chileaudiovisual.cultura.gob.cl/archi-
vos/documentos/Infografia\%20Cine\%20DICIEMBRE\%202017.pdf 
quienes dialoga o a quienes confronta. Estos elementos se vinculan casi como una amalgama y se retroalimentan, al punto que configuran o reconfiguran la propia realidad (Kuhn, 1991; Colaizzi, 2007; Iadevito, 2014).

Recepción y mediación se acentúan a partir de la empatía de los espectadores. Según Igartúa y Muñiz existen tres modos de expresar empatía: la empatía emocional, "que alude a la capacidad de sentir lo que los protagonistas sienten"; la empatía cognitiva, que "permite que el espectador imagine cuáles son los pensamientos, sentimientos y estados mentales" que explican el mundo de los personajes, y la experiencia de "sentirse como si uno mismo fuera uno de los personajes" (2008, p. 33).

Sentir esa emoción en una de esas tres dimensiones o en la combinación de dos o de las tres no es irrelevante para el espectador y su entorno social porque, dicen los teóricos, la empatía genera consecuencias. Barker (2005), Slater y Rouner (2002) y Cohen (2001) explican que cuanto mayor es la identificación del público con los protagonistas de una historia audiovisual, más crece la posibilidad de que la persuasión alcance los niveles necesarios para que el receptor incorpore los valores, actitudes y comportamientos que se recrean en ese contenido de ficción, al punto que puede disminuir de forma notoria la capacidad crítica (Igartúa y Muñiz, 2008).

En el cine chileno contemporáneo se observa la recreación de circunstancias poco afines a la mujer contemporánea pero sí a los estereotipos de género que han definido a la sociedad local hasta ahora. Los personajes de la ficción asumen roles y actitudes en ámbitos que no siempre son una mímesis de la vida presente, sino que plantean las deformaciones que perpetúan estereotipos y reduccionismos (Iadevito, 2014). Esto se observa, sobre todo, en el espacio en que transcurre su vida, las tareas que desempeñan dentro y fuera del hogar, y en las expectativas que los personajes femeninos tienen acerca de su vida presente y futura.

Esas deformaciones acerca de las posibilidades o planteamientos de vida de hombres y mujeres de la ficción se han analizado de forma exhaustiva desde la década de 1970 en otras partes del mundo, cuando se creó -por ejemplola línea de investigación que unió la relación teórica entre el cine y los estudios de género en Estados Unidos y Gran Bretaña. Eso dio pie a que surgieran centros de estudios y publicaciones periódicas con una temática amplia y variada tales como el trabajo de Harry Benshoff y Sean Griffin sobre las representaciones de raza, clase, género y sexualidad en el cine estadounidense (2011); la investigación de Linda Williams acerca del cuerpo femenino en el cine (1991); la de Teresa de Lauretis (1991); y, sobre todo, la información que publica de forma anual el centro Media, Diversity \& Social Change de la Universidad de Southern California, y que lidera Stacey Smith (2005-2017).

Las relaciones de género se desenvuelven, según el Programa de Naciones Unidas para el Desarrollo 
(PNUD), en tres ámbitos o esferas. La esfera pública se refiere al ámbito laboral, al mercado, la educación, el Estado, la política y la capacidad de asociación. La esfera privada incluye el espacio doméstico, la amistad y las relaciones de pareja. Y la individual hace referencia a la subjetividad personal y a la construcción biográfica individual (PNUD, p. 15). Por género se entiende una identidad "creada por las sociedades que no responde a una naturaleza fija e intemporal" (PNUD, 2010, p. 14). Esta definición es coincidente con las que proponen De Lauretis (1996) y Butler (2001). Ambas autoras critican que los asuntos de género se planteen en la vida cotidiana y en las representaciones mentales de forma binaria.

Para De Lauretis, género es una representación que repercute en la vida concreta de las personas, es un concepto construido que se implanta a través de los discursos institucionales y de la industria cultural y que se desarrolla en los procesos de socialización y en el ámbito académico (1996, p. 7-34). Butler, por su parte, sostiene que ese proceso de creación simbólica ocurre en un sistema de tensiones y relaciones de poder que debe y puede ser deconstruido. Lo masculino y lo femenino no constituyen una oposición binaria. Las identidades de género no poseen carácter inmutable y la heterosexualidad no debe considerarse como algo normativo y obligatorio (2001, p. 33-67). Es por eso que, según Butler, la opción de género es libre.

En este trabajo se describe y analiza con profundidad la presencia de este- reotipos acerca del papel de la mujer en la sociedad de acuerdo al relato cinematográfico actual. No se aborda la cuestión de género desde la ideología, sino que se analizan los personajes en su condición de hombre o mujer que enfrentan las exigencias que se les plantean a diario. Para ello se replica la metodología propuesta por Smith en un corpus compuesto por una amplia muestra de cine chileno producido entre 2000 y 2016.

\section{Metodología}

Según los informes que publica anualmente el Consejo Nacional de la Cultura y las Artes y la Cámara de Exhibidores y Multisalas de Chile (CAEM), entre 2000 y 2016 se estrenaron 311 películas chilenas y 2.705 extranjeras. La asistencia prefirió las extranjeras $(93,3 \%)$ entre las que se encontraron las películas dirigidas a un público amplio y que contaron con un sistema de promoción comercial intenso.

El mercado chileno considera que una película que llega o supera los 100.000 espectadores es un éxito de taquilla. Un 10,93\% de las películas chilenas producidas entre 2000 y 2016 alcanzó esa meta, una cifra considerable si se tiene en cuenta que el promedio de asistentes a películas extranjeras es de 82.712. Ese porcentaje está compuesto por 33 títulos, que son los que se incluyen en este estudio. De esa forma se prioriza en el análisis las preferencias del público local. En la Tabla 1 se encuentra el listado de películas que conforman el universo de este trabajo: 
Tabla 1. Películas incluidas

\begin{tabular}{|c|c|c|c|}
\hline $\mathbf{N}^{\circ}$ & Título & Año de estreno & $\mathrm{N}^{\circ}$ de espectadores \\
\hline 1 & Fuga & 2006 & 100,516 \\
\hline 2 & Los debutantes & 2003 & 107,800 \\
\hline 3 & El derechazo & 2013 & 109,669 \\
\hline 4 & Lokas & 2008 & 117,096 \\
\hline 5 & Ojos Rojos & 2010 & 119,037 \\
\hline 6 & Cachimba & 2004 & 122,335 \\
\hline 7 & Mujeres infieles & 2004 & 139,386 \\
\hline 8 & Promedio rojo & 2004 & 143,895 \\
\hline 9 & Gloria & 2013 & 144,717 \\
\hline 10 & Che Kopete & 2007 & 175,695 \\
\hline 11 & Rojo, la película & 2006 & 180,996 \\
\hline 12 & 3:34 Terremoto en Chile & 2011 & 181,906 \\
\hline 13 & Qué pena tu familia & 2013 & 192,350 \\
\hline 14 & Papelucho y el marciano & 2007 & 193,495 \\
\hline 15 & Alma & 2015 & 199,415 \\
\hline 16 & Qué pena tu boda & 2011 & 200,679 \\
\hline 17 & No & 2012 & 211,958 \\
\hline 18 & Grado 3 & 2009 & 240,716 \\
\hline 19 & Argentino QL & 2016 & 276,735 \\
\hline 20 & Ogú y Mampato en Rapa & 2002 & 296,999 \\
\hline 21 & El bosque de Karadima & 2015 & 307,695 \\
\hline 22 & El rey de los huevones & 2006 & 319,470 \\
\hline 23 & Fuerzas especiales & 2014 & 321,146 \\
\hline 24 & Taxi para tres & 2001 & 338,563 \\
\hline 25 & Radio corazón & 2007 & 364,004 \\
\hline 26 & Barrio universitario & 2013 & 367,128 \\
\hline 27 & Violeta se fue a los cielos & 2011 & 387,443 \\
\hline 28 & Sub-terra & 2003 & 483,905 \\
\hline 29 & Machuca & 2004 & 656,579 \\
\hline 30 & El ciudadano Kramer & 2013 & 713,445 \\
\hline 31 & Sexo con amor & 2003 & 990,696 \\
\hline 32 & Sin filtro & 2016 & $1,290,926$ \\
\hline 33 & Stefan vs. Kramer & 2012 & $2,088,375$ \\
\hline
\end{tabular}

Fuente: Elaboración propia 
Cuatro quedaron fuera del estudio por diferentes razones. Dos son películas animadas, destinadas a un público infantil (Papelucho y el marciano y Ogú y Mampato en Rapa). Otra es el documental sobre la Selección de fútbol de Chile, Ojos rojos (2010); y la cuarta corresponde al filme Ché Kopéte (2007), que no se encuentra disponible en formato físico y/o digital. Tampoco existe en los archivos de la Cineteca Nacional de Chile y la producción de la película no dispone de ella

La investigación se abordó con un enfoque mixto, siguiendo la metodología que aplican los dos centros de referencia que inspiraron este trabajo, Gender in the Media, en la Universidad de Southern California (USC), y el Center for the Study of Women in Television and Film, en la Universidad de San Diego.

En ambos casos se utilizó análisis de contenido, una técnica de investigación que permite describir de forma sistemática y cuantitativa el contenido manifiesto de la comunicación (Neuendorf, 2002). Consiste en aplicar unas reglas fijadas previamente para medir la frecuencia con que aparecen los elementos de interés en un conjunto múltiples datos conforme a los propósitos de la investigación.

Tabla 2. Variables aplicadas a la codificación de los personajes

\begin{tabular}{|l|l|}
\hline Perfil dramático & Rol dramático \\
\cline { 2 - 2 } & Narrador \\
\cline { 2 - 2 } & Objetivo dramático \\
\hline Perfil demográfico & Sexo \\
\cline { 2 - 2 } & Género \\
\cline { 2 - 2 } & Edad \\
\cline { 2 - 2 } & Raza/Etnia aparente \\
\cline { 2 - 2 } & Estado civil \\
\cline { 2 - 2 } & Estatus parental \\
\cline { 2 - 2 } & Ámbito laboral \\
\hline Perfil social & Tipo de rol \\
\cline { 2 - 2 } & Clase social aparente \\
\cline { 2 - 2 } & Fidelidad a la pareja \\
\cline { 2 - 2 } & Posición de liderazgo \\
\cline { 2 - 2 } & Ropa insinuadora \\
\hline & Ropa provocativa \\
\cline { 2 - 2 } & Desnudez parcial \\
\hline & Desnudez total \\
\hline
\end{tabular}

Fuente: Elaboración propia 
Se definieron dos unidades de análisis. La primera fue cada autor de las películas, entendido como directores, guionistas y productores $(\mathrm{N}=209)$, los roles de producción clave para medir la presencia femenina detrás de cámaras. Siguiendo el criterio utilizado por el estudio Gender Inequality in 500 Popular Films (Annenberg School for Communication \& Journalism, USC, 2013) se tomaron como referencia los nombres que figuran en las fichas del portal IMDb.com, la base de datos de cine y televisión más exhaustiva a nivel mundial.

La segunda unidad de análisis fue cada personaje que tuviese al menos una línea de diálogo comprensible o que, sin hablar, desarrollara una acción relevante para la trama de la película $(\mathrm{N}=684)$. Con el objetivo de entender cuánto incide la variable género en la creación de personajes, se elaboró un libro de códigos que incluyó 18 variables. Se realizó el visionado de cada película y a cada personaje se le aplicó la lista completa de categorías Se recogieron 12.312 datos.

La variable rol dramático replica el criterio que utilizó Lauzen (2014 y 2016) en un estudio similar y que admite tres respuestas:

1. Protagonista: la película cuenta su historia o es contada desde su punto de vista.

2. Personaje secundario: aparece en más de una escena y actúa como instrumento para la acción de la historia.

3. Personaje terciario: aunque aparezca en más de una escena, no actúa como instrumento para la acción de la historia.

También se midió la presencia de un narrador, es decir, un personaje que cuenta la historia en voz en off.

La tercera variable del perfil dramático de los personajes, su objetivo dramático, hace referencia a aquello que el personaje persigue o busca durante la historia. Se contemplaron cinco opciones de respuesta:

1. Esfera pública: busca algo vinculado con el trabajo, el mercado, la educación, el Estado, la política y lo asociativo.

2. Esfera privada: busca algo vinculado con el espacio doméstico, la amistad y las relaciones de pareja.

3. Esfera individual: busca algo vinculado con la construcción bibliográfica individual y la subjetividad personal.

4. Conjunto: su búsqueda combina más de una esfera.

5. No aplica: imposible determinar un objetivo.

Para las variables de representación demográfica se siguió el criterio de los estudios de referencia (Lauzen, 2016 y Smith et al., 2013). Sexo responde a la categoría biológica (hombre o mujer) y género corresponde a la identidad sexual (femenino, masculino, gay, lesbiana, bisexual o transexual). Para medir la edad se establecieron cinco posibilidades: 0 a 5, 6 a 12, 13 a 20, 21 a 39, 40 a 64 y 65 y más.

Siguiendo las clasificaciones de los estudios de referencia y adaptándolas a la demografía chilena, la variable raza o etnia aparente incluyó cinco opciones 
de respuesta: blanco caucásico, blanco latino, negro, indígena y otro.

El estado civil de los personajes podía ser soltero, casado, pareja estable no casada, pareja estable pero no se conoce el estado civil, separado, divorciado, viudo y desconocido.

Se codificó también el estatus parental, considerando ocho posibilidades: padre o madre con pareja heterosexual; padre o madre con pareja homosexual; no es padre ni madre, para los personajes a partir de los 21 años sin hijos; padre o madre solo, para familias monoparentales; madre soltera, para familias monoparentales en las que nunca hubo presencia del padre; desconocido, cuando no se sabe si el personaje tiene hijos o con quién los tiene; y no aplica, para los personajes de 0 a 20 años sin hijos.

Las opciones de codificación que se aplicaron al ámbito laboral fueron: profesional (ámbito que requiere de un título profesional); técnico (formación profesional); comercio (tiendas, almacenes); servicio (dependientes de mantenimiento, limpieza, etc.); desconocido (trabaja, pero no se sabe en qué ámbito); y no aplica (no trabaja o no se sabe si trabaja).

El tercer grupo de variables se aplica a la representación social, y se definieron con el objetivo de reconocer el uso de estereotipos. La pregunta clave fue en qué esfera transcurre la vida del personaje. Las opciones resultaron ser los cuatro ámbitos en los que, según el PNUD (2010, p. 14), se plantean los mayores desafíos para la equidad de género en Chile y que son: las normas y las le- yes, los símbolos culturales, las fuerzas de mercado y las relaciones de poder, las que, a su vez, se concretan en la esfera pública, la privada y la individual.

La definición del tipo de rol responde a las preguntas: ¿̇a qué esfera de la vida del personaje se le da más importancia en la película?, ¿dónde se mueve la mayor parte del tiempo? Las cuatro opciones de respuesta coinciden con las de la variable objetivo dramático (esfera pública, esfera privada, esfera individual y conjunto).

Se midió también la clase social aparente de los personajes: alta, media alta, media, media baja y baja. También se contempló la respuesta desconocido para casos extremos en los que resultaba imposible clasificar al personaje en alguna de las opciones.

Para los personajes con pareja, se codificó si mostraban fidelidad o en algún momento su pareja los engañaba. Las opciones desconocido (el personaje tiene pareja, pero no se sabe cómo es la relación) y no aplica (no tiene pareja o no se sabe si la tiene) fueron incluidas.

Para la posición de liderazgo, se siguió el criterio empleado por la investigación It's a man's (celluloid) world (Universidad de San Diego, 2015), que considera a un personaje líder cuando dos o más personajes siguen sus indicaciones o comportamientos, ya sea en el terreno formal (organización, trabajo) o informal (familia, amistades).

En el estudio de USC se define la hipersexualización a partir de una serie de variables relativas al tipo de vestimenta y a la desnudez (ya sea parcial o total) de los personajes. De acuerdo con 
el estudio de Smith et al. (2013, p. 5) la tendencia demuestra que los contenidos audiovisuales refuerzan el concepto de mujer objeto y que suele valorarse más la apariencia del cuerpo que la capacidad artística de la mujer. En este caso se establecieron cuatro categorías:

1. Ropa insinuadora: invita a querer ver más; en las mujeres: vestimenta ajustada en la cadera, corta y/o que marca la figura del escote.

2. Ropa provocativa: muestra una in- tención o actitud deliberada de provocar; en las mujeres; vestimenta muy ajustada, muy corta $y / o$ con mucha exposición del pecho.

3. Desnudez parcial: en ropa interior, traje de baño; en hombres, también cuando tienen el torso desnudo.

4. Desnudez total: totalmente desnudo (aunque el plano no deje verlo todo) o desnudo de la cintura hacia abajo; en mujeres, también cuando tienen el torso descubierto.

Tabla 3. Cruce de variables para los personajes

\begin{tabular}{|l|l|}
\hline Pregunta & Variables cruzadas \\
\hline ¿Qué presencia tienen las mujeres y los hombres como personajes? & Sexo \\
\hline $\begin{array}{l}\text { ¿Qué presencia tienen las mujeres como protagonistas, personajes } \\
\text { secundarios y personajes terciarios, y cuál los hombres? }\end{array}$ & Sexo y rol dramático \\
\hline ¿Qué tipo de objetivos persiguen las mujeres y cuáles los hombres? & Sexo y objetivo dramático \\
\hline ¿Qué presencia tiene cada género en los personajes? & Sexo y género \\
\hline ¿Qué edades representan las mujeres y cuáles los hombres? & Sexo y edad \\
\hline $\begin{array}{l}\text { ¿Qué razas o etnias aparentan representar las mujeres y cuáles los } \\
\text { hombres? }\end{array}$ & Sexo y raza/etnia aparente \\
\hline ¿Qué estado civil representan las mujeres y cuáles los hombres? & Sexo y estado civil \\
\hline ¿Qué estatus parental representan las mujeres y cuáles los hombres? & Sexo y estatus parental \\
\hline ¿En qué ámbitos trabajan las mujeres y en cuáles los hombres? & Sexo y ámbito laboral \\
\hline $\begin{array}{l}\text { ¿En qué esfera se mueven las mujeres durante la historia y en cuáles } \\
\text { los hombres? }\end{array}$ & Sexo y clase social aparente \\
\hline ¿Qué tan fieles e infieles son las mujeres y cuánto los hombres? & Sexo y fidelidad de pareja \\
\hline ¿Qué tan líderes son las mujeres y cuánto los hombres? & Sexo y posición de liderazgo \\
\hline $\begin{array}{l}\text { ¿Cuántas mujeres son representadas con ropa insinuadora en al } \\
\text { menos una escena, y cuántos hombres? }\end{array}$ & Sexo y ropa insinuadora \\
\hline $\begin{array}{l}\text { ¿Cuántas mujeres son representadas con ropa provocativa en al } \\
\text { menos una escena, y cuántos hombres? }\end{array}$ & Sexo y ropa provocativa \\
\hline $\begin{array}{l}\text { ¿Cuántas mujeres son representandas parcialmente desnudas en al } \\
\text { menos una escena, y cuántos hombres? }\end{array}$ & Sexo y desnudez parcial \\
\hline $\begin{array}{l}\text { ¿Cuántas mujeres son representadas totalmente desnudas en al } \\
\text { mena escena, y cuántos hombres? }\end{array}$ & Sexo y desnudez total \\
\hline
\end{tabular}


Si un personaje mostraba al menos una de estas variables como positiva, se lo consideró "hipersexualizado". También se contempló la opción de respuesta no aplica para personajes de edad 0 a 12.

Los resultados se procesaron con Statta v.13, para responder a las preguntas que dieron origen a esta investigación. La primera pregunta era: ¿qué presencia tienen las mujeres detrás de cámara en el cine chileno? Para esto se cuantificó la variable género de todos los autores: cuántos hombres y cuántas mujeres ocupaban puestos de dirección, guion y producción en las películas analizadas. Y la segunda fue: ¿̇cuál es la incidencia de la variable género en el perfil sociodemográfico de los personajes, en los roles que se les atribuyen y en la hipersexualización?

La Tabla 3 detalla las preguntas formuladas para los personajes y las variables que se cruzaron para responderlas.

\section{Resultados}

La primera medición recoge la presencia de hombres y mujeres en la dirección, el guion y la producción. El ratio es favorable a los hombres $(6,7$ hombres por cada mujer). En la industria internacional el promedio es de 3,9 (Smith et al. 2013, p. 3; Lauzen, 2014, p. 1). En el gráfico 1 se observa la proporción de autoría de acuerdo con la variable género y en la Tabla 4 se detallan la distribución según el rol que hombres y mujeres ejercen en la producción audiovisual.

Grafico 1. Directores, guionistas y productores en Chile (2000-2016)

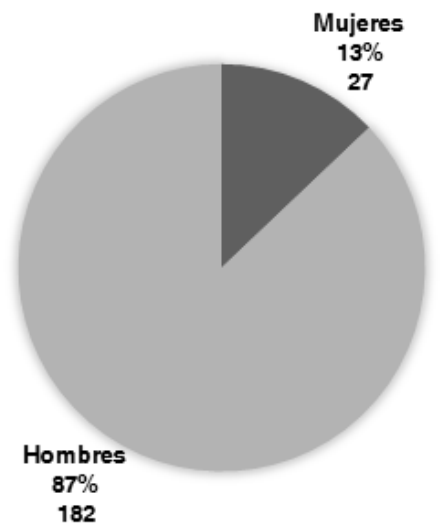

Fuente: Elaboración propia 
Tabla 4. Distribución de género en los autores

\begin{tabular}{|l|ll|ll|}
\hline & Mujeres & & \multicolumn{2}{l|}{ Hombres } \\
\hline Directores & $0 \%$ & & $100 \%$ & $\mathrm{~N}=32$ \\
\hline Guionistas & $6,34 \%$ & $\mathrm{~N}=4$ & $93,65 \%$ & $\mathrm{~N}=59$ \\
\hline Productores & $20,17 \%$ & $\mathrm{~N}=23$ & $79,82 \%$ & $\mathrm{~N}=91$ \\
\hline
\end{tabular}

Fuente: Elaboración propia

Llama la atención que ninguna de las películas que logró más de 100.000 espectadores entre 2000 y 2016 haya sido dirigida por una mujer. Lo mismo ocurre con los guionistas. Solo cuatro mujeres se desempeñaron como guionistas cuando 59 hombres asumieron esa tarea. La participación de las mujeres crece en las tareas de producción, una labor fundamental que transcurre detrás de escena pero que mantiene el estereotipo de que la mujer se desempeña mejor y está más cómoda en un trabajo de segunda línea.

La segunda unidad de análisis incluyó, como ya se ha dicho, a todos los personajes que tuviesen al menos una línea de diálogo en las películas $(\mathrm{N}=684)$. En este caso se contabilizó la presencia de 263 mujeres y 421 hombres (un 38,5\% y un $61,5 \%$ respectivamente). Esto implica un ratio de 1.6 personajes masculinos por cada personaje femenino. Una proporción muy similar se observa en el género de los personajes protagonistas: 21 mujeres y 35 hombres. Este resultado es mayor que el que se recoge en los estudios de Lauzen (2014, p. 2) y Smith et al. (2013, p. 1) para referirse al cine estadounidense. En esos casos se recogieron un $30 \%$ y un $28,4 \%$ respectivamente. El cine producido en Estados Unidos prioriza a los protagonistas hombres.

Grafico 2. La mujer según su rol dramático

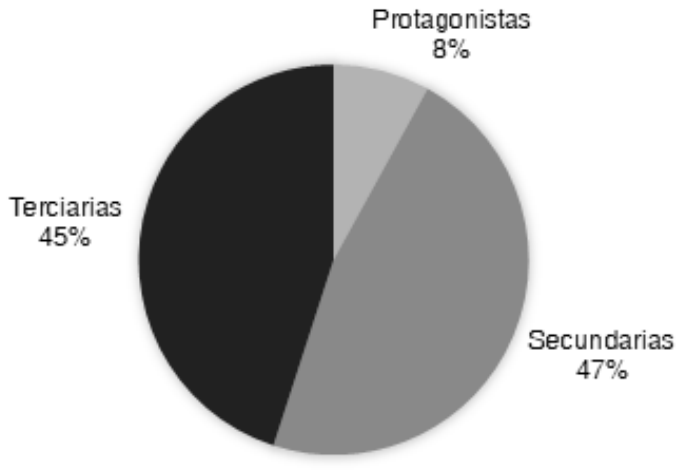

Fuente: Elaboración propia 
Por otra parte, solo ocho personajes cumplieron el papel de narrador con voz en off. Por sí misma esa cifra no resulta tan significativa. Lo que sí sorprende es que de los ocho, siete sean hombres y solo haya una mujer. Se prioriza entonces la voz del narrador masculino. No hay espacio para que la mujer cuente su propia historia.

Frente a la pregunta por el espacio en que se concreta el objetivo dramático de los personajes cabe señalar que fue posible determinarlo en el $100 \%$ del N. Se reconoció que 133 del total $(19,4 \%)$ buscan lograr una meta en la esfera pública, espacio vinculado al trabajo, al mercado, la educación, el Estado, la política o lo asociativo. De ese total, las mujeres representan el 18,8\%. La mayoría de las historias se concentran en la esfera privada -aquella que transcurre en el espa- cio doméstico, en una relación de amistad o de pareja- (146 mujeres y 135 hombres) y un pequeño porcentaje se mantiene en la esfera individual (4 mujeres y 7 hombres).

Se registraron 34 mujeres y 83 hombres que se desempeñaban en más de una esfera. Sin embargo, el estereotipo de género se mantiene tanto si este valor se suma a los resultados de la esfera pública como a los de la esfera privada: menos mujeres en lo público y más mujeres en lo privado.

La diversidad sexual está apenas representada. No existen personajes transexuales, sólo tres mujeres y dos hombres son bisexuales y un $7,1 \%$ se declara gay y un $0,7 \%$ de las mujeres son lesbianas.

A continuación, se incluye la Tabla 5 que resume los demás datos demográficos de los personajes:

Tabla 5. Datos demográficos de personajes femeninos y masculinos

\begin{tabular}{|l|r|r|}
\hline Variable & Mujeres & Hombres \\
\hline Edad & & \\
\hline 0 a 05 & 3 & 5 \\
\hline 6 a 12 & 10 & 12 \\
\hline 13 a 20 & 28 & 30 \\
\hline 21 a 39 & 120 & 128 \\
\hline 40 a 64 & 88 & 223 \\
\hline 65 o más & 14 & 23 \\
\hline Raza o etnia aparente & & \\
\hline Blanco caucásico & 22 & 11 \\
\hline Blanco medio & 243 & 404 \\
\hline Negro & 0 & 4 \\
\hline Indígena & 0 & 0 \\
\hline Estado civil & & \\
\hline Soltero & 40 & 75 \\
\hline Casado o en pareja & 87 & 92 \\
\hline Separado o divorciado & 3 & 6 \\
\hline Viudo & 4 & 4 \\
\hline Desconocido & 129 & 24 \\
\hline
\end{tabular}

Fuente: Elaboración propia 
La insistencia en la presencia de personajes caucásicos no se condice con la realidad. La ausencia de personajes que se asemejen a una población mestiza se explica, quizás, con los resultados de un estudio sobre prejuicios y discriminación social realizado por la Universidad de Talca (Chile) en 2018. Allí se detalla que el biotipo de los chilenos es de piel morena, estatura baja y pelo oscuro y que existe la creencia de que las personas que cuentan con mayor poder adquisitivo tienen otro biotipo: blanco, de mayor estatura, rasgos y colorido nórdico. Se asocia entonces el biotipo con un nivel de vida más alto. Es así que un 42,1\% de los chilenos considera que el pelo rubio es más distinguido que el pelo oscuro (Aguirre y Castro, 2018). En este caso, el cine chileno acentúa ese estereotipo en las mujeres y las presenta sobre todo rubias: un $66,66 \%$ de los personajes de raza blanca caucásica es mujer.

A su vez cabe destacar que la concentración etaria se sitúa en el tramo 40 a 64. No se observaron resultados significativos cuando se cruzaron las variables sexo y fidelidad en la pareja.

En cuanto a cuáles son las circunstancias en que hombres y mujeres ejercen la maternidad o la paternidad, 11 personajes femeninos aparecen como madres solteras. Ninguno de los hombres se encuentra en una situación similar. Se codificó en esta categoría a aquellas personas que crían a sus hijos solos, que no volvieron a contraer un vínculo de pareja y nunca retomaron el contacto con el padre o la madre de sus hijos.

Se cuantificó la ocupación laboral de todos los personajes. Un 79,97\% $(\mathrm{N}=547)$ de los personajes contaba con la edad para desempeñarse en un trabajo remunerado (se excluyó a niños y adolescentes). Entre ellos, 42,77\% contaba con título universitario, 5,4\% eran técnicos con formación profesional, $6,03 \%$ trabajaban en el comercio y $13,52 \%$ en servicios. No se conoce la ocupación de un $32,71 \%$ de los personajes.

Si a esto se agrega la variable sexo, llama la atención que hay muchos más hombres entre los profesionales y entre quienes aparecen en la actividad comercial: el 69,65\% entre los profesionales y $60,61 \%$ entre los comerciantes.

Solo un 41, 66\% de los personajes ejerce una posición de liderazgo, entendida como aquella en la que por lo menos dos personas obedecen sus indicaciones. Esto puede ocurrir en el ámbito público y también en el privado. La brecha es, en este caso, especialmente notoria: los hombres triplican a las mujeres.

Por último, corresponde analizar los resultados de las cuatro variables referidas a hipersexualización, que tienen que ver con la vestimenta y con el manejo del desnudo o semidesnudo. Como se señaló más arriba, no se incluyeron en esta medición a los niños (personajes de 0 a 12 años). Para determinar que un personaje aparece como hipersexualizado debía, al menos, clasificar en alguna de esas categorías. Y fue el caso de 85 personajes femeninos $(67,46 \%)$ y 41 masculinos $(32,54 \%)$. Es importante señalar también que 52 personajes clasificaron en dos o más variables. De ese total, 94,23\% fueron mujeres. 
Gráfico 3. Liderazgo masculino y femenino

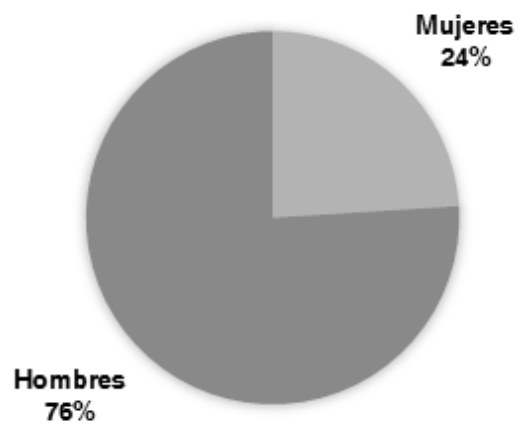

Fuente: Elaboración propia

\section{Discusión y conclusiones}

En el informe del PNUD (2010) se detalla cómo se agrupan los chilenos con respecto a las representaciones culturales de género. De acuerdo con ese estudio, la mayoría de los chilenos considera que los hombres mandan y proveen y las mujeres son madres y esposas, es mejor mantener la diferencias -juntos, pero no revueltos- y la moral tradicional con respecto a las tareas domésticas y a la participación en el mundo público. Y también es normal que la mujer "lo de todo" y que los hombres mantengan ciertas ventajas en su vida cotidiana.

De acuerdo con los resultados obtenidos en este estudio, puede concluirse que la producción cinematográfica local que se exhibió entre 2000 y 2016 y que logró más de 100 mil espectadores, acentúa los estereotipos de género y recrea situaciones que retrasan e impiden el acceso de la mujer a la esfera pública. Las mujeres del cine chileno se mantie- nen en los espacios domésticos, participan apenas en actividades que implican ejercer liderazgo y además se las representa hipersexualizadas.

No existe, por tanto, una reconfiguración social sino más bien una retroalimentación de situaciones límite, que mantienen a la mujer en inferioridad de condiciones con respecto a su autonomía física, en la toma de decisiones y en su independencia económica. Las situaciones que se recrean son, en su mayoría, verosímiles, aunque poco actuales.

Los roles de género se plantean todavía de forma binaria, salvo excepciones mínimas. Esa forma aparece incluso como normativa y obligatoria. No hay excepciones. Las mujeres son quienes se ocupan de las tareas domésticas y de la crianza de los hijos. Sus anhelos vitales se circunscriben al hogar y a los problemas personales.

La hipersexualización es quizá uno de los resultados más llamativos. Esto consi- 
derando el drama de la violencia física y sicológica contra la mujer, así como el número de femicidios que se cometen en Chile y el impacto negativo de la cosificación femenina en el desarrollo de las adolescentes. El cine chileno no parece haber atendido las proclamas de los movimientos feministas y tampoco las políticas públicas desarrolladas con el objetivo de erradicar la violencia contra la mujer y las referencias estereotipadas al lugar que ocupa en la sociedad, sino que mantiene una imagen de mujer sexualizada y cosificada, alguien de quien se puede disponer o descartar. Parece interesante continuar esta investigación aplicando la misma metodología en otros corpus de análisis. En concreto, en el cine de autores menores de 40 años. Se plantea así la posibilidad de que los estereotipos de género estén menos presentes en las nuevas generaciones.

\section{Bibliografía}

Aguirre, M. \& Castro, M. (2018). Prejuicio y discriminación racial en Chile. Universidad de Talca. Disponible en: http://www.cenem.utalca.cl/docs/publicaciones/Prejuicio_y_discriminacion_racial_en_Chile.pdf

Barker, M. J. (2005). The Lord of the Rings and 'Identification' A Critical Encounter. European Journal of Communication, 20(3), 353-378.

Benshoff, H. M., \& Griffin, S. (2011). America on film: Representing race, class, gender, and sexuality at the movies. John Wiley \& Sons.

Butler, J. (2001). Mecanismos psíquicos del poder: teorías sobre la sujeción (Vol. 68). Universitat de València.

Cohen, J. (2001). Defining identification: A theoretical look at the identification of audiences with media characters. Mass communication \& society, 4(3), 245-264.

Colaizzi, G. (2007). La pasión del significante: teoría de género y cultura visual. Biblioteca nueva.

De Lauretis, T. (2018). Aesthetic and feminist theory: rethinking women's cinema. In Feminist Art Criticism (pp. 143-162). Routledge.

Fredrickson, B. L., \& Roberts, T. A. (1997). Objectification theory: Toward understanding women's lived experiences and mental health risks. Psychology of women quarterly, 21(2), 173-206.

Iadevito, P. (2014). Teorías de género y cine. Un aporte a los estudios de la representación. Universitas Humanística, (78), 211-237.

Igartua, J. J., \& Muñiz, C. (2008). Identificación con los personajes y disfrute ante largometrajes de ficción. Una investigación empírica.

Kuhn, A., \& Recuero, S. I. (1991). Cine de mujeres: feminismo y cine. Romero, Madrid: Cátedra. Lauzen, M. (2014). The Funny Business of Being Tina Fey: constructing a (feminist) comedy icon. Feminist Media Studies, 14(1), 106-117.

Lauzen, M. M. (2016). It'sa man's (celluloid) world: Portrayals of female characters in the top 100 films of 2015. Center for the Study of Women in Television and Film. Retrieved from: http:// womenintvfilm.sdsu.edu/files/2015_Its_a_Mans_Celluloid_World_Report.pdf.

Neuendorf, K. A. (2016). The content analysis guidebook. Sage. 
Programa de las Naciones Unidas para el Desarrollo (2010). Género: Los desafíos de la igualdad.

Slater, M. D., \& Rouner, D. (2002). Entertainment-education and elaboration likelihood: Understanding the processing of narrative persuasion. Communication Theory, 12(2), 173-191.

Smith, S. L., Choueiti, M., Scofield, E., \& Pieper, K. (2013). Gender inequality in 500 popular films: Examining on-screen portrayals and behind-the-scenes employment patterns in motion pictures released between 2007-2012. University of Southern California Annenberg School for Communication \& Journalism.

Smith, S., Choueiti, M, Pieper, K. (2017). Inequality in 900 Popular Films: Examining Portrayals of Gender, Race/Ethnicity, LGBT, and Disability from 2007-2016. Disponible en. https://annenberg.usc.edu/inequality-900-popular-films

Williams, L. (1991). Film bodies: Gender, genre, and excess. Film Quarterly, 44(4), 2-13. Doi: $10.2307 / 1212758$ 